\title{
Hydrogen-Storage Properties and Structure Characterization of Melt-Spun and Annealed Mg-Ni-Nd Alloy *1
}

\author{
Jingtian Yin ${ }^{* 2,1}$, Kazuhide Tanaka ${ }^{* 3,1}$ and Nobuo Tanaka ${ }^{2}$ \\ ${ }^{1}$ Department of Materials Science and Engineering, Nagoya Institute of Technology, Nagoya 466-8555, Japan \\ ${ }^{2}$ Department of Applied Physics, Nagoya University, Nagoya 464-0814, Japan
}

\begin{abstract}
The hydriding/dehydriding characteristics of a Mg-rich $\mathrm{Mg}-\mathrm{Ni}-\mathrm{Nd}$ alloy produced by melt-spinning and subsequent annealing have been investigated. This alloy absorbs $\sim 4.7$ mass $\%$ hydrogen $(\mathrm{H} / \mathrm{M} \sim 1.5)$ quickly between 423 and $573 \mathrm{~K}$ and wholly desorbs it at moderate speeds above $453 \mathrm{~K}$. Transmission electron microscope observations and selected-area electron diffraction analyses of this alloy before and after hydriding demonstrate that it consists of multiple phases of $\mathrm{Mg}_{2} \mathrm{Ni}$ and Nd-hydride precipitated uniformly in a nano-structured $\mathrm{Mg}$ matrix. The fast reaction kinetics is caused by an interplay between a catalytic action of the Nd-hydrides and the surrounding nano-sized Mg grains which quickly store or evolve hydrogen across the interfaces.
\end{abstract}

(Received October 18, 2001; Accepted November 22, 2001)

Keywords: hydrogen storage, magnesium-nickel-neodymium alloy, melt-spinning, nanocomposite structure, hydriding/dehydriding kinetics, catalyst, high-resolution transmission electron microscopy

\section{Introduction}

The poor hydriding-dehydriding (H/D) kinetics of Mgbased alloys is generally attributed to the poor dissociation ability of metallic $\mathrm{Mg}$ for hydrogen molecules and also to the formation of surface hydrides which hinder the further transport of hydrogen into the matrix. ${ }^{1-3)}$ The addition of a catalyst appears to be a simple and effective method to overcome these problems. In our previous works, we have shown that certain Mg-rich Mg-Ni-RE and Mg-Pd-RE alloys (RE: rare earth) exhibit high $\mathrm{H}$-capacities and excellent kinetics, ${ }^{4-7)}$ where a rare-earth element such as $\mathrm{La}$ and $\mathrm{Nd}$ is considered to act as an efficient catalyst for dissociating $\mathrm{H}_{2}$ molecules and transferring the $\mathrm{H}$ atoms to the surrounding $\mathrm{Mg}$ matrix. In addition, reducing the grains of the matrix is thought to be another efficient way to improve the reaction kinetics because it may enhance the inward transport of $\mathrm{H}$ atoms along the grain boundaries and thereby reduce the depth of the hydride layer. The effectiveness of refining the microstructures for improving the reaction kinetics has really been proved for Mg-based alloys fablicated by mechanical alloying ${ }^{3,8,9)}$ and melt-spinning., ${ }^{40)}$

The objective of the present study is firstly to examine the hydrogen-storage characteristics of a Mg-rich $\mathrm{Mg}-\mathrm{Ni}$ alloy added with a small amount of $\mathrm{Nd}$ and subjected to melt-spinning and annealing, and secondly to characterize its microstructure by high-resolution transmission electron microscopy (HRTEM) and electron diffraction (ED) for discussing a possible $\mathrm{H} / \mathrm{D}$ mechanism in the alloy.

An alloy with composition $\mathrm{Mg}_{86} \mathrm{Ni}_{10} \mathrm{Nd}_{4}$ was prepared in the same way as described previously. ${ }^{5,6)}$ Amorphous ribbons ( $\sim 20 \mu \mathrm{m}$ thick and $\sim 1 \mathrm{~mm}$ wide) were fabricated from this alloy by melt-spinning using a single copper roll, and they were crystallized by annealing at $553 \mathrm{~K}$ in vacuum. After being pulverized into powder of 70 mesh $(<210 \mu \mathrm{m})$, they were

\footnotetext{
${ }^{* 1}$ This Paper was Presented at the Autumn Meeting of the Japan Institute of Metals, held in Fukuoka, on September 23, 2001.

${ }^{* 2}$ Graduate Student, Nagoya Institute of Technology.

${ }^{* 3}$ Corresponding author. E-mail: tanaka@mse.nitech.ac.jp
}

subjected to ten hydriding (for $15 \mathrm{ks}$ under $3 \mathrm{MPa} \mathrm{H}_{2}$ ) and dehydriding (for $10 \mathrm{ks}$ in vacuum) cycles at $573 \mathrm{~K}$ to achieve full activation and stabilization. The kinetics of the H/D process was measured with a volumetric method using a Sievertstype apparatus. Structure observation and phase analysis were employed with HRTEM and ED techniques using a $200 \mathrm{keV}$ microscope (JEOL:JEM-2010) for as-prepared (before activation), H-charged (after first hydriding to saturation at $573 \mathrm{~K}$ ) and $\mathrm{H}$-discharged (after dehydriding at $573 \mathrm{~K}$ for $11 \mathrm{ks}$ ) powder specimens.

Figure 1(a) shows the hydriding behavior of the asprepared sample (melt-spun and crystallized state) in the initial activation process at $573 \mathrm{~K}$, where we find that after only one H/D cycle the alloy manifests an excellent reactivity with hydrogen, providing much faster kinetics compared with that of a binary $\mathrm{Mg}-\mathrm{Ni}$ alloy without $\mathrm{Nd} .{ }^{5)}$ After the second H/D cycle, the sample reaches a maximum hydriding rate and it is stably kept in the later cycles. The temperature dependence of the hydriding behavior of the completely activated and stabilized sample (after subjecting to ten H/D cycles at $573 \mathrm{~K}$ ) is shown in Fig. 1(b). As is evident from the figure, this alloy exhibits remarkably enhanced hydriding kinetics above $423 \mathrm{~K}$ absorbing 3.5-4.5 mass $\% \mathrm{H}$ within $1 \mathrm{ks}$. The absorption rate increases with increasing temperature reaching the maximum rate at 523-573 K. In addition, this alloy exhibits substantially rapid desorption kinetics above $453 \mathrm{~K}$, as shown in Fig. 1(c), although the desorption rate is much suppressed below $423 \mathrm{~K}$. Approximately $80 \%$ of the maximum capacity of hydrogen can be desorbed within $15 \mathrm{ks}$ at $453 \mathrm{~K}, 2 \mathrm{ks}$ at $473 \mathrm{~K}$ and $1 \mathrm{ks}$ at $523 \mathrm{~K}$ in vacuum.

HRTEM images and the corresponding ED pattern of asprepared specimen are shown in Figs. 2(a)-(d). In Fig. 2(a), we can observe three different phases coexisting in the visual area: a bright matrix, spherical small particles which are homogeneously embedded in the bright matrix, and a much larger dark phase at the left bottom. Figure 2(c) shows the morphology of the spherical particles with a size of 20 $30 \mathrm{~nm}$ and very fine grains with a size of $2-5 \mathrm{~nm}$ constitut- 

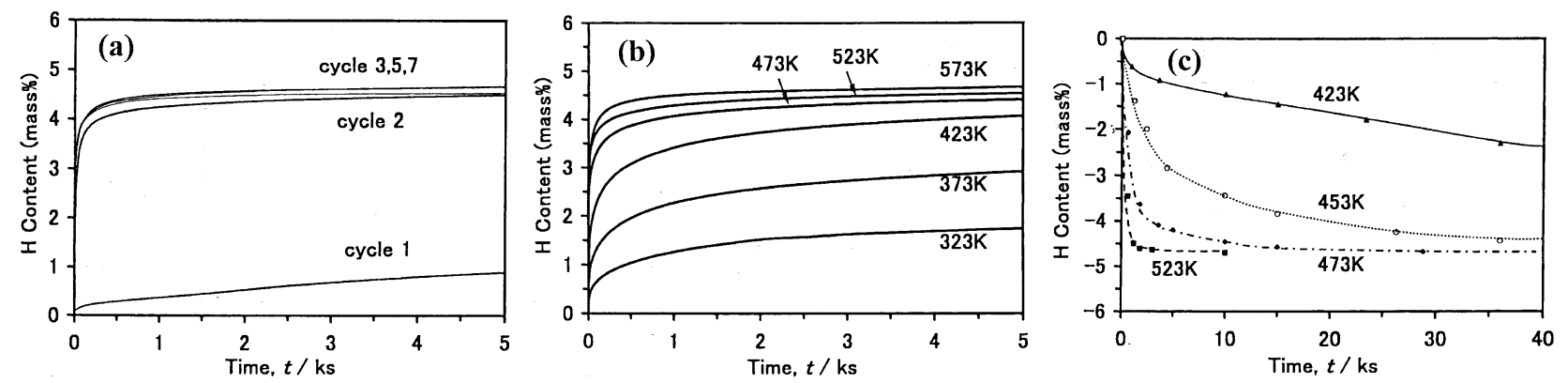

Fig. 1 Activation behavior of the $\mathrm{Mg}-\mathrm{Ni}-\mathrm{Nd}$ alloy for the first 7 cycles at $573 \mathrm{~K}$; (b) hydriding of the fully activated and stabilized sample at $323-573 \mathrm{~K}$; (c) dehydriding of the fully activated and stabilized sample at $423-523 \mathrm{~K}$.

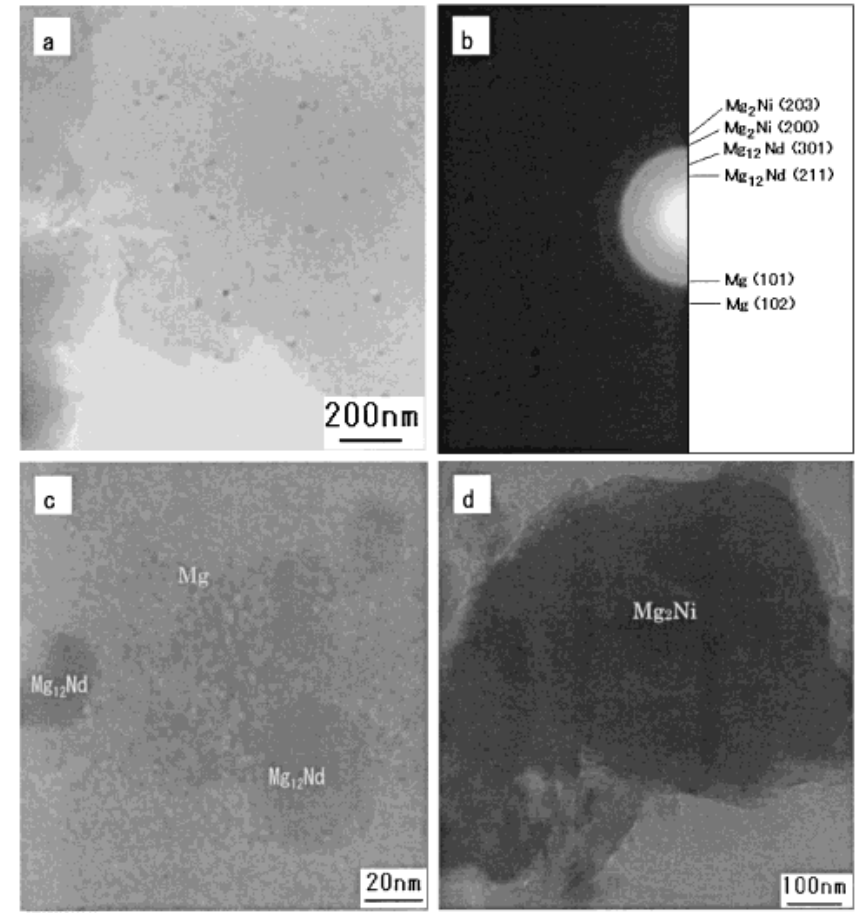

Fig. 2 HRTEM images (a), (c),( d) and ED pattern (b) of the as-prepared specimen.

ing the bright matrix. The morphology of the dark phase with $\sim 1 \mu \mathrm{m}$ in size is shown in Fig. 2(d). Figure 2(b) displays the ED pattern from the whole visual area. Analysis of this diffraction pattern reveals that the as-prepared sample comprises of $\mathrm{Mg}, \mathrm{Mg}_{12} \mathrm{Nd}$ and $\mathrm{Mg}_{2} \mathrm{Ni}$ mixed phases, in accordance with our earlier result based on X-ray diffraction. ${ }^{5,6)}$ Selected-area electron diffraction (SAED) analyses for the three kinds of phases indicate that the bright matrix consists of nano-sized $\mathrm{Mg}$ grains which give rise to continuous diffraction rings, while the spherical particles represent $\mathrm{Mg}_{12} \mathrm{Nd}$ compound which causes diffraction spots, and the large dark region corresponds to $\mathrm{Mg}_{2} \mathrm{Ni}$ giving a smaller number of diffraction spots.

The HRTEM images of the H-charged specimen are illustrated in Figs. 3(a) and (c), where fine spherical particles with a size of about 20-50 nm dispersed uniformly in a bright matrix containing finer grains (approximately $2-8 \mathrm{~nm}$ in size) are revealed, together with a coarse dark phase $(>100 \mathrm{~nm})$ visible in certain regions. From the ED pattern shown in Fig. 3(b), coupled with SAED analyses, the matrix and the spherical particles were identified as $\mathrm{MgH}_{2}$ and $\mathrm{Nd}_{2} \mathrm{H}_{5}$, respectively. The coarse dark phase was confirmed as $\mathrm{Mg}_{2} \mathrm{NiH}_{4}$. Thus the present HRTEM investigation reveals that the $\mathrm{Mg}_{12} \mathrm{Nd}$ phase in the as-prepared sample disproportionated into $\mathrm{MgH}_{2}$ and $\mathrm{Nd}_{2} \mathrm{H}_{5}$ after the hydriding, whereas the $\mathrm{Mg}$ and $\mathrm{Mg}_{2} \mathrm{Ni}$ phases transformed into $\mathrm{MgH}_{2}$ and $\mathrm{Mg}_{2} \mathrm{NiH}_{4}$, respectively.

Figures 4(a)-(c) show HRTEM images and the corresponding ED pattern of the $\mathrm{H}$-discharged specimen. Although the discharged specimen exhibits a similar morphology to the as-prepared and $\mathrm{H}$-charged ones, the phase conversion has practically occurred upon dehydriding. The ED pattern reveals that $\mathrm{Mg}$ and $\mathrm{Mg}_{2} \mathrm{Ni}$ have been recovered from their own hydride phases but the $\mathrm{Nd}_{2} \mathrm{H}_{5}$ phase remains unchanged after dehydriding. It has been confirmed that $\mathrm{Mg}$, $\mathrm{Nd}_{2} \mathrm{H}_{5}$ and $\mathrm{Mg}_{2} \mathrm{Ni}$ phases are present as the matrix $(2-5 \mathrm{~nm}$ in grain size), spherical particles $(20-50 \mathrm{~nm})$ and larger particles $(>100 \mathrm{~nm})$, respectively, in the discharged specimen.

A summary of the characteristics of the ED patterns is given in Table 1, where the interplanar spacing $d$ and the feature of the diffraction pattern are specified for all the existing phases in the specimens.

We have shown that the $\mathrm{Mg}_{86} \mathrm{Ni}_{10} \mathrm{Nd}_{4}$ alloy produced by melt-spinning and subsequent annealing is readily activated in hydrogen atmosphere and can stably absorb and desorb more than 4.5 mass $\% \mathrm{H}$ in moderate speeds above $453 \mathrm{~K}$. These excellent hydrogen-storage properties of the alloy are strongly related with a nano-sized multiphase structure of the alloy. In the following, we interpret the H/D processes of this alloy on the basis of the HRTEM and ED results shown above.

The amorphous phase formed by melt-spinning simultaneously decomposes into $\mathrm{Mg}, \mathrm{Mg}_{12} \mathrm{Nd}$ and $\mathrm{Mg}_{2} \mathrm{Ni}$ phases upon crystallization. The two compound phases are embedded in a $\mathrm{Mg}$ matrix composed of very fine grains of 2-5 nm. In the first activation process, most of the $\mathrm{Mg}_{12} \mathrm{Nd}$ phase decomposes into $\mathrm{Mg}$ and $\mathrm{Nd}$ hydrides via a irreversible disproportionation reaction:

$$
4 \mathrm{Mg}_{12} \mathrm{Nd}+53 \mathrm{H}_{2} \Rightarrow 48 \mathrm{MgH}_{2}+2 \mathrm{Nd}_{2} \mathrm{H}_{5}
$$

The $\mathrm{Nd}_{2} \mathrm{H}_{5}$ hydride once formed in this process is thermally stable and efficiently acts as a chemical catalyst to assist the following reversible $\mathrm{H} / \mathrm{D}$ reactions of $\mathrm{Mg}$ and $\mathrm{Mg}_{2} \mathrm{Ni}$ :

$$
\begin{aligned}
& \mathrm{Mg}+\mathrm{H}_{2} \Leftrightarrow \mathrm{MgH}_{2} \\
& \mathrm{Mg}_{2} \mathrm{Ni}+2 \mathrm{H}_{2} \Leftrightarrow \mathrm{Mg}_{2} \mathrm{NiH}_{4}
\end{aligned}
$$

Pressure-composition isotherms (PCTs) for $\mathrm{Mg}-\mathrm{Ni}-\mathrm{Nd}$ al- 

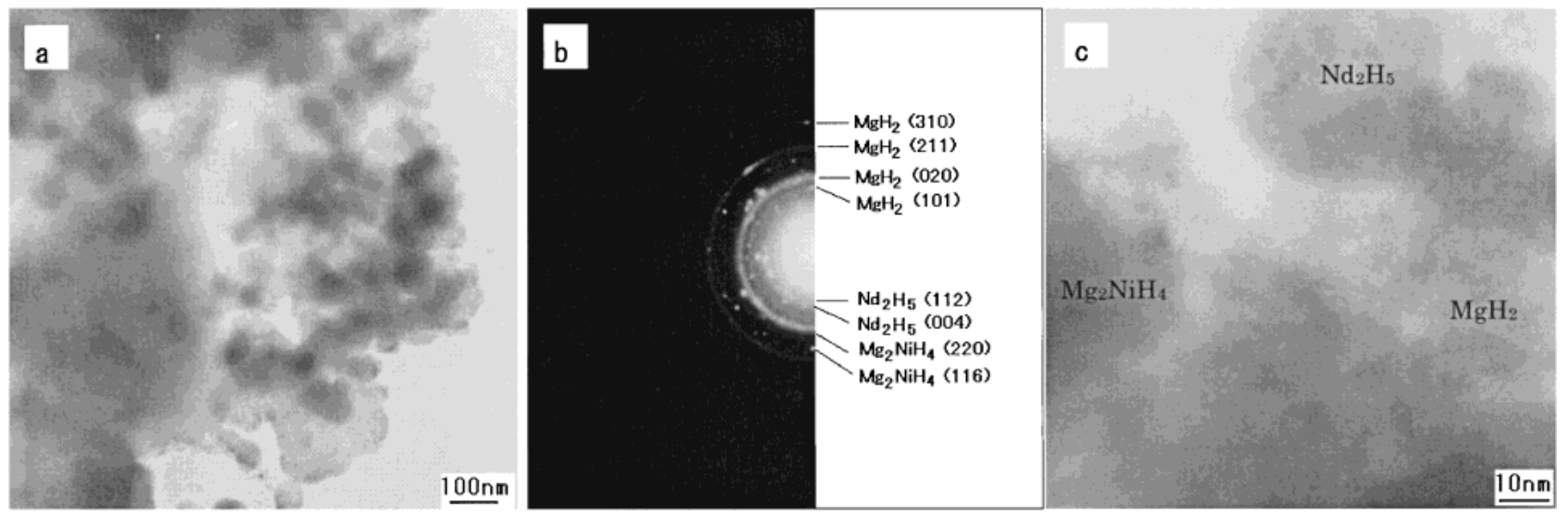

Fig. 3 HRTEM images (a), (c) and ED pattern (b) of the H-charged specimen.
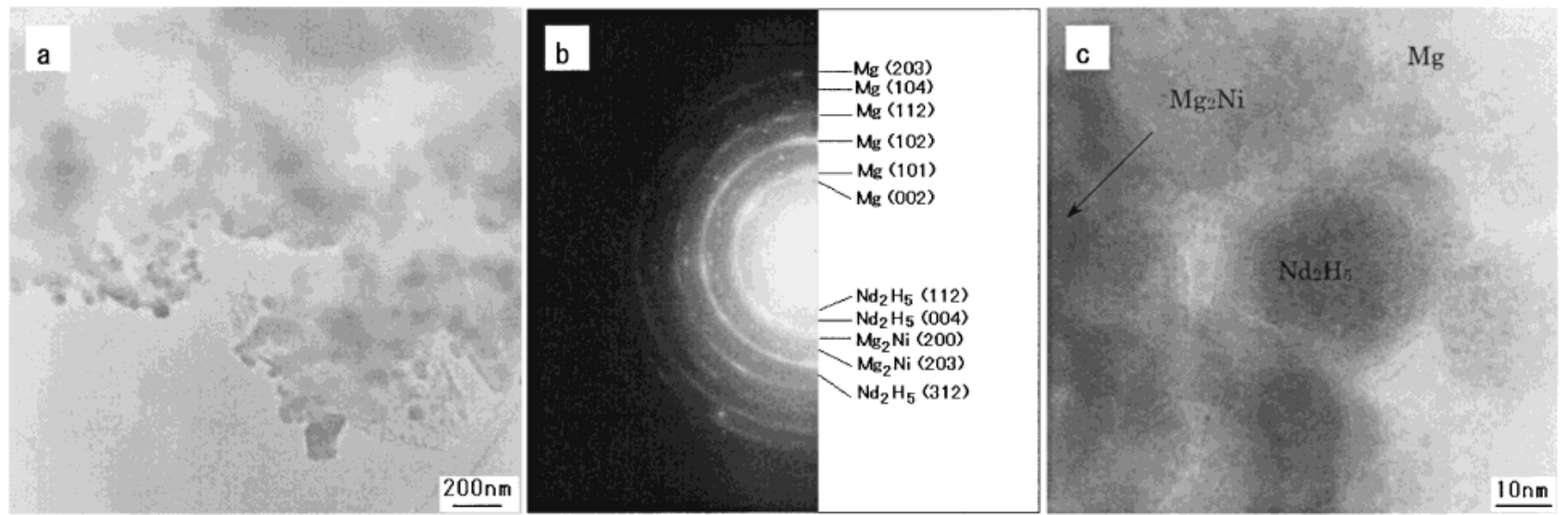

Fig. 4 HRTEM images (a), (c) and ED pattern (b) of the H-discharged specimen.

Table 1 Characteristics of the ED patterns for the as-prepared, H-charged and H-discharged specimens.

\begin{tabular}{|c|c|c|c|c|c|c|c|c|}
\hline \multicolumn{3}{|c|}{ As-prepared } & \multicolumn{3}{|c|}{ H-charged } & \multicolumn{3}{|c|}{ H-discharged } \\
\hline$d$-spacing/0.1 nm & Phase $(h k l)$ & Character & $d$-spacing $/ 0.1 \mathrm{~nm}$ & Phase $(h k l)$ & Character & $d$-spacing $/ 0.1 \mathrm{~nm}$ & Phase $(h k l)$ & Character \\
\hline \multirow[t]{2}{*}{3.62} & $\mathrm{Mg}_{12} \mathrm{Nd}(211)$ & $S$ & & & & & & \\
\hline & & & 3.13 & $\mathrm{Nd}_{2} \mathrm{H}_{5}(112)$ & $\mathrm{S}$ & 3.13 & $\mathrm{Nd}_{2} \mathrm{H}_{5}$ & $\mathrm{~S}$ \\
\hline \multirow[t]{2}{*}{2.97} & $\mathrm{Mg}_{12} \mathrm{Nd}(301)$ & $S$ & & & & & & \\
\hline & & & 2.72 & $\mathrm{Nd}_{2} \mathrm{H}_{5}(004)$ & $S$ & 2.72 & $\mathrm{Nd}_{2} \mathrm{H}_{5}(004)$ & $S$ \\
\hline 2.60 & $\mathrm{Mg}(002)$ & $\mathrm{R}$ & & & & 2.60 & $\operatorname{Mg}(002)$ & $\mathrm{R}$ \\
\hline \multirow[t]{2}{*}{2.56} & $\mathrm{Mg}_{12} \mathrm{Nd}(202)$ & S & & & & & & \\
\hline & & & 2.51 & $\mathrm{MgH}_{2}(101)$ & $\mathrm{R}$ & & & \\
\hline \multirow[t]{2}{*}{2.45} & $\operatorname{Mg}(101)$ & $\mathrm{R}$ & & & & 2.45 & $\operatorname{Mg}(101)$ & $\mathrm{R}$ \\
\hline & & & 2.26 & $\mathrm{MgH}_{2}(020)$ & $\mathrm{XR}$ & & & \\
\hline 2.25 & $\mathrm{Mg}_{2} \mathrm{Ni}(200)$ & S & 2.25 & $\mathrm{Mg}_{2} \mathrm{NiH}_{4}(220)$ & S & 2.25 & $\mathrm{Mg}_{2} \mathrm{Ni}(200)$ & S \\
\hline 2.01 & $\mathrm{Mg}_{2} \mathrm{Ni}(203)$ & S & 1.95 & $\mathrm{Mg}_{2} \mathrm{NiH}_{4}(116)$ & S & 2.01 & $\mathrm{Mg}_{2} \mathrm{Ni}(203)$ & S \\
\hline \multirow[t]{3}{*}{1.90} & $\operatorname{Mg}(102)$ & $\mathrm{XR}$ & & & & 1.90 & $\operatorname{Mg}(102)$ & $\mathrm{XR}$ \\
\hline & & & 1.68 & $\mathrm{MgH}_{2}(211)$ & $\mathrm{R}$ & & & \\
\hline & & & 1.57 & $\mathrm{Nd}_{2} \mathrm{H}_{5}(312)$ & $S$ & 1.57 & $\mathrm{Nd}_{2} \mathrm{H}_{5}(312)$ & $S$ \\
\hline \multirow[t]{2}{*}{1.49} & $\operatorname{Mg}_{12} \mathrm{Nd}(631)$ & S & 1.51 & $\mathrm{MgH}_{2}(220)$ & $\mathrm{R}$ & & & \\
\hline & & & 1.43 & $\mathrm{MgH}_{2}$ (310) & $\mathrm{R}$ & & & \\
\hline 1.36 & $\operatorname{Mg}(112)$ & $\mathrm{R}$ & & & & 1.36 & $\operatorname{Mg}(112)$ & $\mathrm{R}$ \\
\hline \multirow[t]{2}{*}{1.29} & $\mathrm{Mg}_{12} \mathrm{Nd}(613)$ & S & & & & & & \\
\hline & & & & & & 1.22 & $\mathrm{Nd}_{2} \mathrm{H}_{5}$ & $S$ \\
\hline 1.17 & $\operatorname{Mg}(104)$ & $\mathrm{R}$ & 1.16 & $\mathrm{MgH}_{2}(321)$ & $\mathrm{R}$ & 1.17 & $\operatorname{Mg}(104)$ & $\mathrm{R}$ \\
\hline
\end{tabular}

Key: S-spot; R-ring; XR-strong ring

loys ${ }^{4-6)}$ indicate that in the hydriding process the reaction (2) precedes (3) owing to a lower equilibrium pressure for the former than the latter, and vice versa in the dehydriding process.
In parallel with the above $\mathrm{H} / \mathrm{D}$ reactions, the $\mathrm{Nd}$ hydride with a particle size of $20-50 \mathrm{~nm}$ may also undergo a reversible re- 


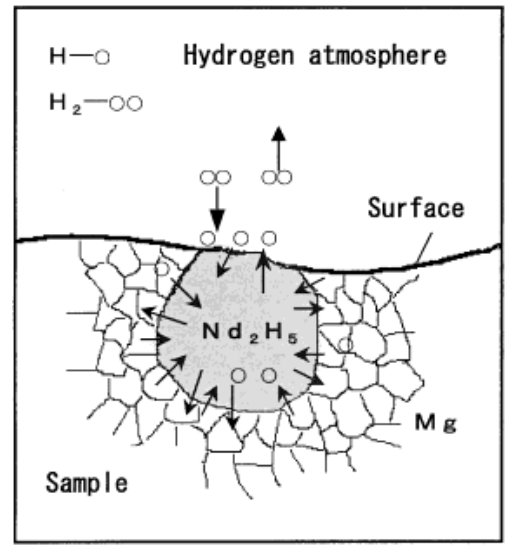

Fig. 5 Catalystic processes of a $\mathrm{Nd}_{2} \mathrm{H}_{5}$ particle for dissociating or recombining $\mathrm{H}_{2}$ molecules at the surface, and for evolving or absorbing $\mathrm{H}$ atoms at the interface with $\mathrm{Mg}$ nanograins.

action:

$$
2 \mathrm{Nd}_{2} \mathrm{H}_{5}+\mathrm{H}_{2} \Leftrightarrow 4 \mathrm{NdH}_{3}
$$

This reaction appears to be important to bestow a catalytic activity to the $\mathrm{Nd}$ hydride. ${ }^{7)}$ Since $\mathrm{NdH}_{3}$ is less stable than $\mathrm{Nd}_{2} \mathrm{H}_{5}$, the former can readily decompose to the latter by evolving hydrogen and transmitting it, as a gateway, either to the surrounding $\mathrm{Mg}$ nanograins in the hydriding process, or to the surrounding hydrogen atmosphere in the dehydriding process, as schematically illustrated in Fig. 5. Here, the $\mathrm{Nd}$ hydride formed near the surface of a grain of the powder also behaves as an efficient catalyst for dissociating or recombining the $\mathrm{H}_{2}$ molecules. In addition, the role of nano- sized grain structure of the $\mathrm{Mg}$ matrix is quite important to enhance the H/D kinetics, where hydrogen atoms can readily be transported inward or outward by diffusion along the grain boundaries existing in high density.

\section{Acknowledgements}

This work is partly supported by the Grant-in-Aid for Scientific Research on Priority Area A of 'New Protium Function' from The Ministry of Education, Science, Sports and Culture of Japan. The financial support from NEDO is also acknowledged.

\section{REFERENCES}

1) L. Schlapbach: Hydrogen in Intermetallic Compounds II, ed. L. Schlapbach (Springer, Berlin, 1992) pp. 1-95.

2) N. Gérard and S. Ono: Hydrogen in Intermetallic Compounds II, ed. L. Schlapbach (Springer, Berlin, 1992) pp. 65-195.

3) A. Zaluska, L. Zaluski and J. O. Ström-Olsen: J. Alloys Compd. 288 (1999) 217-225.

4) K. Tanaka, Y. Kanda, M. Furuhashi, K. Saito, K. Kuroda and H. Saka: J. Alloys Compd. 293-295 (1999) 521-525.

5) J. Yin, T. Yamada, O. Yoshinari and K. Tanaka: Mater. Trans. 42 (2001) $712-716$.

6) J. Yin and K. Tanaka: Proc. 4th Pacif. Rim Int. Conf. Adv. Mater. \& Proces (PRICM 4, 2001, Japan Inst. Metals) pp. 453-456.

7) T. Yamada, J. Yin and K. Tanaka: Mater. Trans. 42 (2001) 2415-2421.

8) S. Orimo, K. Ikeda, H. Fujii, Y. Fujikawa, Y. Kitano and K. Yamamoto: Acta Mater. 45 (1997) 2271-2278.

9) G. Liang, J. Huot, S. Boily, A. Van Neste and R. Schulz: J. Alloys Compd. 292 (1999) 247-252.

10) T. Spassov and Uwe Köster: J. Alloys Compd. 287 (1999) 243-250. 